Особенности лечения интерстициальной лимфоцитарной болезни легких у пациентов с синдромами иммунной дизрегуляции: клинический пример

\author{
Ю.А. Родина, А.Л. Хорева, И.Н. Абрамова, О.А. Швец, В.И. Бурлаков, \\ Г.В. Терещенко, Д.С. Абрамов, Е.В. Дерипапа \\ ФГБУ «Национальный медицинский исследовательский центр детской гематологии, \\ онкологии и иммунологии им. Дмитрия Рогачева» Минздрава России, Москва
}

Синдромы дизрегуляции (дефицит генов CTLA4, LRBA) относятся к комбинированным первичным иммунодефицитным состояниям с нарушением аутотолерантности за счет дефекта супрессорной функции Т-регуляторных лимфоцитов и характеризуются развитием тяжелых аутоиммунных осложнений. Одно из них - интерстициальная лимфоцитарная болезнь легких (ИЛБЛ), обусловленная патологической гиперплазией бронхо-ассоциированной лимфоидной ткани, что приводит к потере функции легких, сокращая продолжительность жизни пациента. Диагностика ИЛБЛ основывается на патоморфологическом исследовании легочной ткани и радиологических методах визуализации. Таргетная патогенетическая терапия препаратом абатацепт при синдромах дизрегуляции позволяет достичь максимального контроля над аутоиммунными осложнениями, включая ИЛБЛ, и не обладает значимыми побочными эффектами. В статье представлен клинический разбор пациентов с синдромами дизрегуляции и развитием ИЛБЛ с применением таргет-

ной терапии абатацептом.

Ключевые слова: интерстициальная лимфоцитарная болезнь легких, первичный иммунодефицит, дефицит CTLA-4, дефицит LRBA, абатацепт

Родина Ю.А. и соавт. Вопросы гематологии/онкологии и иммунопатологии в педиатрии, 2018; 17 (3): 103-110. DOl: $10.24287 / 1726-1708-2018-17-3-103-110$

\section{Therapy features of interstitial lymphocytic lung disease (ILLD) in patients with immune dysregulation syndromes: case report}

Y.A. Rodina, A.L. Horeva, I.N. Abramova, O.A. Shvets, V.I. Burlakov, G.V. Tereshenko, D.S. Abramov, E.V. Deripapa Dmitriy Rogachev National Medical Research Center of Pediatric Hematology, Oncology, Immunology Ministry of Healthcare of Russian Federation, Moscow

Immune dysregulation syndromes (CTLA4 and LRBA deficiency) belong to the combined primary immunodeficiencies with defective tolerance due to lack of $T$ regulatory lymphocytes function and resulting autoimmune complications. One of them is interstitial lymphocytic lung disease (ILLD), caused by pathologic bronchi-associated lymphoid tissue hyperplasia, progressive loss of lung function and decreased life expectancy. ILLD diagnosis is based on pathomorphological lung changes and radiologic symptoms. Targeted therapy with Abatacept in patients with immune dysregulation syndromes provides control of the autoimmune complications, including ILLD and is well tolerated. Here we demonstrate two cases of patients with immune dysregulation syndromes and ILLD treated with Abatacept. Key words: interstitial lymphocytic lung disease (ILLD), primary immunodeficiency, CTLA4 deficiency, LRBA deficiency, Abatacept

\section{Контактная информация:}

Родина Юлия Александровна, врач аллерголог-иммунолог отделения иммунологии НМИЦ детской гематологии, онкологии и иммунологии им. Дмитрия Рогачева Минздрава России. Адрес: 117997, Москва, ГСП-7, ул. Саморы Машела, 1 E-mail: rodina.julija@rambler.ru

\author{
Correspondence: \\ Julia A. Rodina, MD, allergologis- \\ immunologist of the Immunology \\ Department, Dmitriy Rogachev \\ National Medical Research Center \\ of Pediatric Hematology, Oncology, \\ Immunology Ministry of Healthcare \\ of Russian Federation. \\ Address: Russia 117997, Moscow, \\ Samory Mashela st., 1 \\ E-mail: rodina.julija@rambler.ru
}

П ервичные иммунодефицитные состояния (ПИДС) - это группа разнородных генетически обусловленных заболеваний с подлежащими десектами иммунного ответа [1]. Как известно, ПИДС проявляются не только тяжелыми инфекциями, но и широким спектром аутовоспалительных синдромов, онкологичесских и аутоиммунных заболеваний, в том числе интерстициальной лимфоцитарной болезнью легких (ИЛБЛ) [2]. Впервые ИЛБЛ описана как осложнение общей вариабельной иммунной недостаточности [3], однако особенно высокая часто- та встречаемости этого осложнения (до 52\%) характерна для «новых» моногенных ПИДС из группы иммунной дизрегуляции [4], таких как дефицит CTLA4 (Cytotoxic Tlymphocyte-associated antigen-4) и дефицит LRBA (Lipopolysaccharide-responsive beige-like anchor) $[5,6]$.

Мутации в гене CTLA4 наследуются аутосомно доминантно и приводят к гаплонедостаточности белка CTLA4. Соответствующее этому дефекту заболевание названо «CTLA4-гаплонедостаточность с аутоиммунной инфильттрацией» (CHAl-CTLA4 Haploinsufficiency 
with Autoimmune Infiltration) и характеризуется лимфоцитарной инфильтрацией нелимфоидных органов (легких, кишечника, головного мозга и др.), а также аутоиммунными цитопениями, прогрессивным снижением циркулирующих В-лимфоцитов и сывороточных иммуноглобулинов [7]. В 2012 году описаны 5 пациентов с клиническими признаками синдрома CHAl, со значительным снижением экспрессии CTLA4, но без мутации в соответствующем гене. Было обнаружено, что вторичный дефицит данного рецептора вызван дефектом его регуляторного белка LRBA (Lipopolysaccharide - responsive beige-like anchor), обусловленным аутосомно-рецессивно наследуемыми мутациями в гене LRBA [8]. Таким образом, различные генетические дефекты приводят к сходной клинической картине, о чем пойдет речь в этой статье.

Молекулярные и клеточные основы дефектов CTLA4 и LRBA. LRBA - белок, который относится к семейству pleckstrin homologybeige and Chediak-Higashi-tryptophan aspartic acid dipeptide (PH-BEACH-WD40) белков и экспрессируется в гемопоэтических, нервных и других клетках. Ген LRBA расположен на 4q31.3, содержит 57 экзонов и кодирует белок, состоящий из 2851 аминокислотного остатка [9].

Было установлено, что LRBA является регулятором экспрессии CTLA4 на T-регуляторных (Treg) и активированных Т-лимфоцитах посредством взаимодействия с цитоплазматическим участком этого белка, замедляя его деградацию в лизосомах [10] (рисунок 1).

\section{Рисунок 1}

Модель функционирования молекулы CTLA4 и ее регулятора LRBA

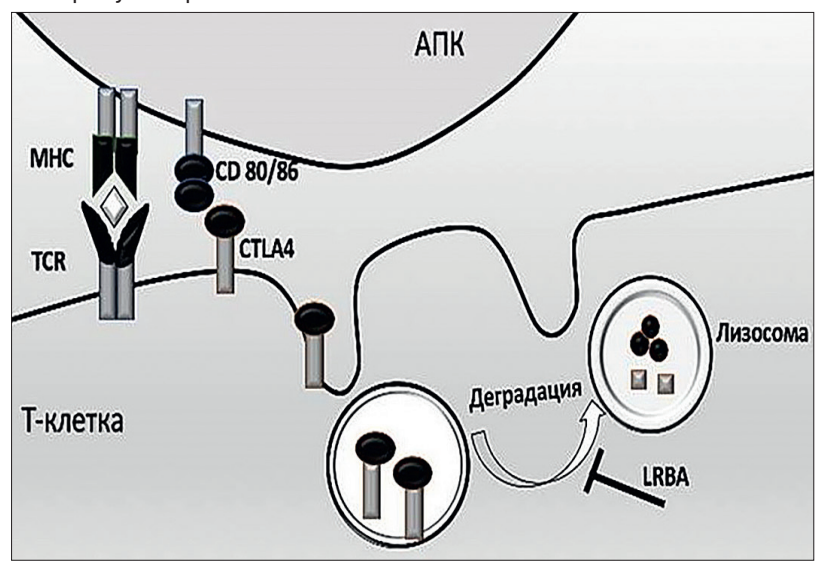

В экспериментах in vitro показано, что дефект белка LRBA приводит к массивной деградации CTLA4, а ингибирование лизосомальной деградации в клетках с дефектом LRBA восстанавливает уровень экспрессии CTLA4 [10].
Таким образом, мутация непосредственно в гене CTLA4 или его регуляторе LRBA приводит к снижению экспрессии CTLA4 или нарушению функции этого белка. Как было упомянуто, молекула CTLA4 экспрессируется на активированных Т-лимсоцитах и Т-регуляторных клетках и играет ключевую роль в поддержании иммунного гомеостаза, ограничивая иммунный ответ путем связывания с лигандами CD80/86 на антигенпрезентирующих клетках (АПК) [11-13], а также путем клеточно-опосредованной супрессии с участием Treg. Было показано, что мутация в гене CTLA4 приводит к нарушению супрессорной функции Treg-клеток in vivo и in vitro [14], клинически напоминая изменения у мышей scurfy c мутацией в гене FOXP3. Важная роль данной молекулы продемонстрирована в опытах на CTLA4 «нокаутированных» мышах, у которых стремительно развивалась фратальная лимфоцитарная инфильтрация органов $[15,16]$.

Клинико-лабораторные признаки дефицита LRBA и CTLA4. Наиболее характерные проявления данных заболеваний - признаки иммунной дизрегуляции и развитие IPEX-подобного (Immune dysregulation, Polyendocrinopathy, Enteropathy, $X$-linked-X-сцепленный синдром иммунной дизрегуляции, полиэндокринопатии и энтеропатии) фенотипа заболевания [17]. Подобно клинической картине при IPEX, у данной группы пациентов нередко с раннего возраста отмечают энтеропатию $\mathrm{c}$ атрофией ворсинок и лимфоцитарной инфильтрацией слизистой оболочки кишечника; поражение легких по типу фолликулярного бронхиолита и лимфоцитарной пневмонии в рамках ИЛБЛ; лимфопролиферативный синдром; аутоиммунные гемолитическую анемию, тромбоцитопению и нейтропению. Реже наблюдаются аутоиммунные эндокринопатии, сахарный диабет 1-го типа, аутоиммунный тиреоидит, а также ревматоидный артрит, псориаз, увеит, миастения гравис и др. [3, 18].

Характерные лабораторные иммунологические показатели: гипогаммаглобулинемия или дисгаммаглобулинемия (с наличием гипериммуноглобулинемии М), снижение $\mathrm{CD}^{+}$Т-лимсоцитов, Treg-лимсоцитов, NK-клеток, выраженный дефицит переключенных В-лимсоцитов «памяти» и снижение/отсутствие экспрессии CTLA4 [7].

Согласно публикациям, в качестве патогенетической терапии при данных ПИДС препаратом выбора является абатацепт (Оренсия) [10] - химерное гуманизированное моноклональное антитело, состоящее из Fc-участка иммуноглобулина G1 и внеклеточного домена CTLA4 [19].

Представляем клинические случаи пациентов в возрасте 5 и 9 лет с генетически доказанными пер- 
вичными иммунодефицитами с иммунной дизрегуляцией - дефицитом LRBA и CTLA4 соответственно, развивших множественные иммунные осложнения, в том числе интерстициальную лимфоцитарную болезнь легких.

\section{Клинические наблюдения}

Пациент № 1: девочка А., 5,5 года, 2013 г.р., в возрасте 3 лет впервые поступила в отделение иммунологии НМИЦ детской гематологии, онкологии и иммунологии им. Дмитрия Рогачева Минздрава России (далее - НМИЦ ДГОИ) с симптомами тяжелого хронического бронхолегочного процесса с целью исключения первичного иммунодефицита.

В анамнезе: раннее (с 2 мес.) начало заболевания с рецидивирующим течением фурункулеза, отита, пневмонии. В последующем (в 2 года) отмечено развитие тяжелого лимфопролиферативного синдрома (печень +6 см, селезенка +8 см из-под края реберной дуги, лимфаденопатия) и трехростковой цитопении (нейтропения - 0,1 × 10\%/л; тромбоцито-

\section{Таблица 1}

Основные результаты лабораторных методов обследования пациентов

\begin{tabular}{|c|c|c|c|}
\hline Показатель & $\begin{array}{c}\text { Пациент } \\
\text { №1 }\end{array}$ & $\begin{array}{c}\text { Пациент } \\
\text { №2 }\end{array}$ & Норма \\
\hline Лейкоциты, $\times 10^{9} / л$ & 3,31 & 7,53 & $7-12$ \\
\hline Гемоглобин, г/л & 95 & 97 & $115-160$ \\
\hline Тромбоциты, г/л, × 109/л & 125 & 206 & $150-400$ \\
\hline Нейтрофилы, $\times 10^{9} / л$ & 0,01 & 3,5 & $2,27-5,66$ \\
\hline Ретикулоциты, \% & 5,49 & 0,8 & $0,2-1,2$ \\
\hline Прямая проба Кумбса & Положит. (++) & Положит. (+) & Отрицат. \\
\hline Иммуноглобулин А, г/л & $<0,246$ & 0,254 & $0,3-1,5$ \\
\hline Иммуноглобулин М, г/л & 5,1 & 0,2 & $0,6-1,8$ \\
\hline Иммуноглобулин G, г/л & 2,3 & 1,9 & $4-14,6$ \\
\hline $\mathrm{CD3}^{+}, \times 10^{9} / л$ & 1,344 & 2,64 & $1,4-2,5$ \\
\hline $\mathrm{CD}^{+} / \mathrm{CD}^{+}, \times 10^{9} / \pi$ & 0,9065 & 1,21 & $0,9-2,0$ \\
\hline $\mathrm{CD}^{+} / \mathrm{CD}^{+}, \times 10^{9} / \pi$ & 0,367 & 1,28 & $0,6-1,9$ \\
\hline $\mathrm{CD}_{19}+, \times 10^{9} /$ л & 0,8203 & 0,53 & $0,7-1,3$ \\
\hline $\mathrm{CD}_{19}{ }^{+} \mathrm{CD} 27^{+}, \lg \mathrm{D}^{-}, \%$ & 3,8 & 4,2 & $8,7-25,6$ \\
\hline $\mathrm{CD}^{-} / \mathrm{CD} 16^{+} / \mathrm{CD}^{2} 6^{+}, \times 10^{9} / л$ & 0,0354 & 0,4 & $0,276-0,896$ \\
\hline Treg (CD $\left.4^{+} \mathrm{CD} 25^{+} \mathrm{CD} 127^{-}\right), \%$ & 2,4 & 3,37 & $5-6,1$ \\
\hline TREC, $\times 10^{5}$ /лейк. & 120 & 170 & $470-4100$ \\
\hline KREC, $\times 10^{5}$ /лейк. & 0 & 0 & $780-7700$ \\
\hline
\end{tabular}

пения - $47 \times 10$ /л и анемия, гемоглобин - 70 г/л), а также (в 2,5 года) появление хронической диареи неинфекционного генеза. Назначение глюкокортикостероидов (ГКС), микофенолата мофетила (ММФ) к купированию симптомов не привело.

При поступлении в отделение иммунологии НМИЦ ДГОИ им. Дмитрия Рогачева тяжесть соматического статуса пациентки была обусловлена выраженным бронхолегочным синдромом с дыхательной недостаточностью 1-2-й степени (малопродуктивный частый кашель, инспираторная одышка, множественные разнокалиберные хрипы, снижение сатурации кислорода до 94\%), лимфопролиферативным синдромом - преимущественно за счет гепатоспленомегалии, энтеропатии. Лабораторно отмечена трехростковая аутоиммунная цитопения (аутоиммунная гемолитическая анемия, нейтропения, тромбоцитопения), повышение сывороточного иммуноглобулина $M$ до 5,1 г/л на фоне глубокого снижения $\lg A$ и $\lg G$, а также снижения количества цитотоксических лимфоцитов $\left(\mathrm{CD}^{+}\right)$, NK-клеток, B-переключенных лимфоцитов «памяти», Т-регуляторных лимфоцитов, TREC; отсутствие KREC (TCR/BCR rearrangement excision circles - маркеров нормального созревания Т- и В-клеточного рецепторов) (таблица 1).

По результатам мультиспиральной компьютерной томографии (МСКТ) органов грудной клетки и брюшной полости в паренхиме легких выявлены субсантиметровые инфильтративные очаги по типу матового стекла (симптом «хлопкового дерева в почках») на фоне диффузного поражения интерстиция, а также лимфаденопатия внутригрудных лимфатических узлов и признаки гепатоспленомегалии. Комплексное микробиологическое исследование бронхоальвеолярного лаважа не выявило причинно-значимого патогена, обусловливающего имеющиеся легочные изменения. Учитывая тяжесть состояния пациента, от проведения биопсии легкого решено было воздержаться. Однако по совокупности клинических и рентгенологических симптомов была диагностирована интерстициальная лимфоцитарная болезнь легких.

Диагностическая фиброэзофагогастродуоденоскопия (ФЭГДС) и колоноскопия также позволили подтвердить иммунное поражение различных отделов желудочно-кишечного тракта: язва луковицы двенадцатиперстной кишки, эрозивный бульбит, терминальный илеит, дифффузный лимфофолликулярный колит, обусловленные диффузной Т-лимфоцитарной инфильтрацией собственной пластинки с множеством апоптотических фигур, крипт-абсцессов, криптита.

На основании совокупности данных заподозрен ПИДС с IPEX-подобным фенотипом. Пациентке проведено молекулярно-генетическое исследование с использованием секвенирования нового поколения 
(NGS, иммунологическая панель), по результатам которого в гене LRBA обнаружена миссенс-мутация c.1359G > C, p.Gln453His, приводящая к повреждению донорного сайта сплайсинга (замена последнего нуклеотида в экзоне), в гомозиготном состоянии. У обоих здоровых родителей подтверждено носительство найденной мутации в гетерозиготном состоянии (рисунок 2 A)

Таким образом, у ребенка в возрасте 5 лет (2018 год) верифицирован первичный иммунодефицит - дефицит LRBA. Учитывая основное заболевание, в ка- честве патогенетической терапии начато лечение препаратом абатацепт (Оренсия) в дозе 10 мг/кг, внутривенно, 1 раз в 14 дней. На фоне терапии отмечены улучшение общего самочувствия, регресс лимфопролисеративного синдрома, нормализация стула, нивелирование цитопении, а также, по результатам МСКТ, стойкая положительная динамика в виде уменьшения интерстициальных и инфильтративных изменений в паренхиме обоих легких и уменьшения размеров конгломерата лимфатических узлов в средостении (рисунки 3 А, Б).

\section{Рисунок 2}

Генеалогические древа пациентов (А - пациентка № 1; Б - пациентка № 2): фигуры, закрашенные черным, - пациенты с подтвержденным генетических дефектом; фигуры, закрашенные наполовину, - здоровые гетерозиготные носители мутации (при аутосомно-рецессивном наследовании дефекта LRBA); фигуры с точкой - гетерозиготные бессимптомные (на момент написания статьи) носители (при аутосомно-доминантном наследовании дефекта CTLA)

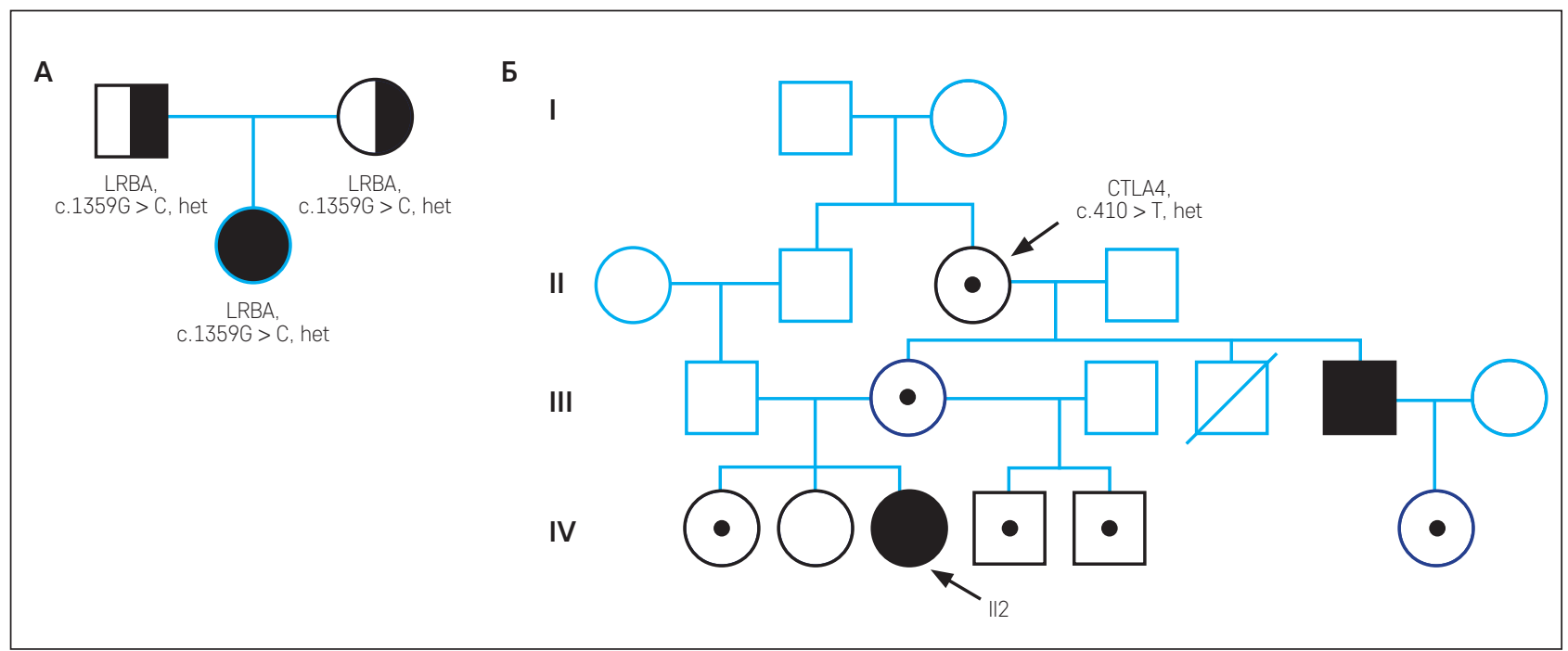

\section{Рисунок 3}

Динамика МСКТ-симптомов ИЛБЛ на фоне проводимой терапии у пациентов № 1 и № 2 .

Пациент № 1: А - до начала лечения; Б - 3 мес. терапии абатацептом.

Пациент № 2: В - до начала терапии; Г, Д - на фоне ритуксимаба (4/8 инфузий соответственно); Е - 6 мес. терапии абатацептом

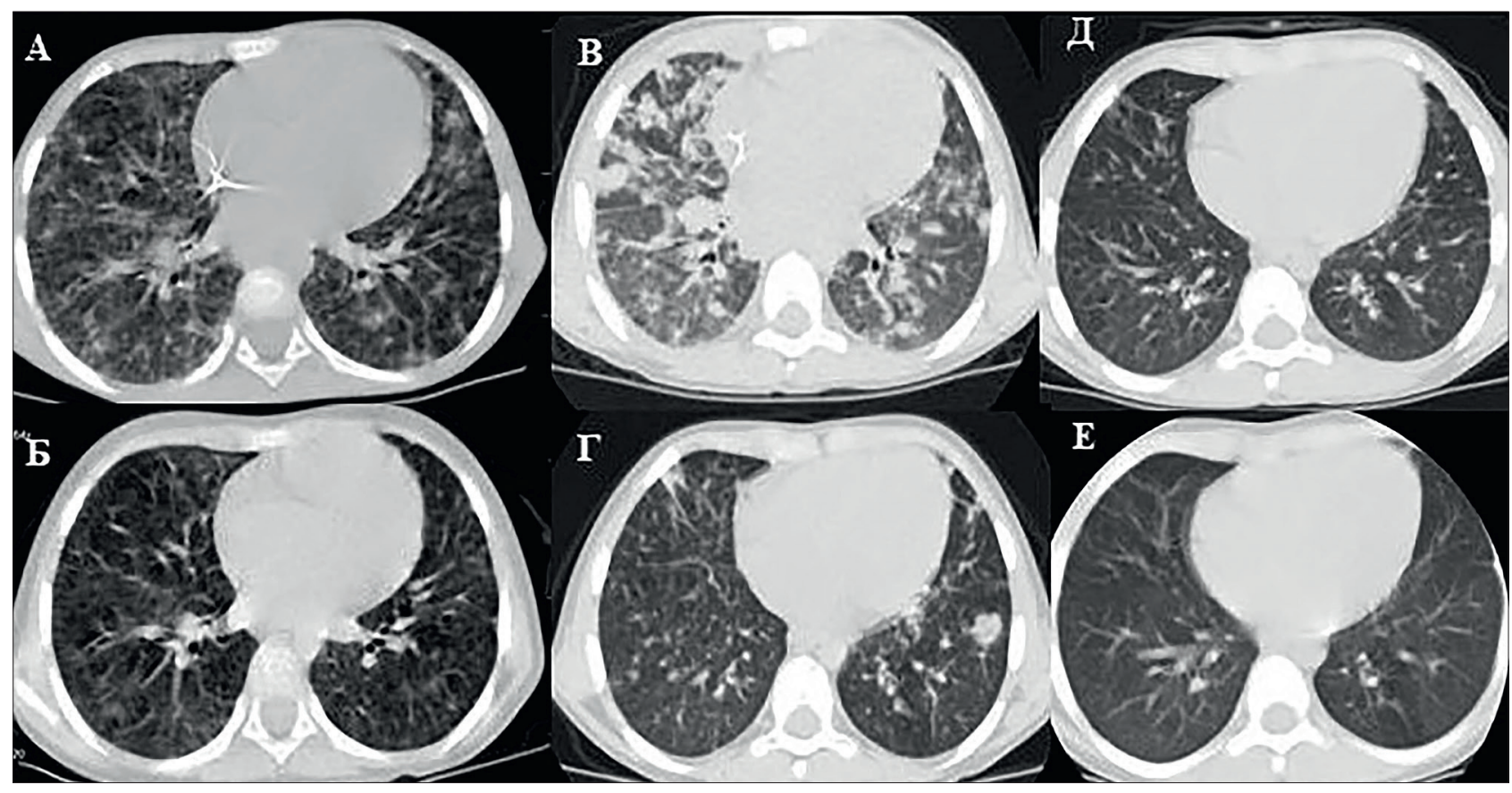


Пациент № 2: девочка Л., 9 лет, 2008 г.р., наблюдается в отделение иммунологии НМИЦ ДГОИ им. Дмитрия Рогачева с 4-летнего возраста с диагнозом «первичный иммунодефицит комбинированный». Пациентка родилась от близкородственного брака (мама и папой - двоюродные брат и сестра) с отягощенным наследственным анамнезом (родной дядя по линии матери умер в возрасте 7 лет от опухоли желудка?); другой родной дядя, тоже по материнской линии, - с тромбоцитопенией, энтеропатией, гипогаммаглобулинемией). Развитие в период грудного возраста - без особенностей.

Анамнез заболевания - с возраста 2 лет, когда появилась диарея, потеря массы тела, отставание в физическом развитии, эпизоды фебрильной лихорадки, частые респираторные вирусные инфекции (до 1-2 раз в месяц). В возрасте 3 лет у пациентки выявлена выраженная гепатоспленомегалия (печень

\section{Таблица 2}

\section{Сравнительная характеристика} клинической картины пациентов

\begin{tabular}{|c|c|c|}
\hline Показатель & Пациент № 1 & Пациент № 2 \\
\hline Генетический дефект & $\begin{array}{c}\text { Ген } L R B A, \\
\text { c. } 1359 \mathrm{G}>\mathrm{C} \text {, hom }\end{array}$ & $\begin{array}{l}\text { Ген CTLA4, } \\
\text { c. } 410 \mathrm{C}>\mathrm{T} \text {, het }\end{array}$ \\
\hline Возраст, пол & 5,5 года, девочка & 9 лет, девочка \\
\hline Возраст манифестации & С рождения & С 2 лет \\
\hline $\begin{array}{l}\text { Интерстициальная } \\
\text { лимфоцитарная болезнь } \\
\text { легких }\end{array}$ & + & + \\
\hline $\begin{array}{l}\text { Лимфопролиферативный } \\
\text { синдром }\end{array}$ & $\begin{array}{c}\text { Гепатоспленомегалия, } \\
\text { лимфаденопатия }\end{array}$ & $\begin{array}{c}\text { Гепатоспленомегалия, } \\
\text { лимфаденопатия }\end{array}$ \\
\hline Цитопения & $\begin{array}{l}\text { 3-ростковая } \\
\text { цитопения }\end{array}$ & $\begin{array}{c}\text { Тромбоцитопения, } \\
\text { анемия }\end{array}$ \\
\hline Иммунная энтеропатия & + & + \\
\hline $\begin{array}{l}\text { Ответ } \\
\text { на «классическую» ИСТ }\end{array}$ & $\begin{array}{c}\text { Кратковременный, } \\
\text { неполный }\end{array}$ & $\begin{array}{c}\text { Кратковременный, } \\
\text { неполный }\end{array}$ \\
\hline Ответ на ритуксимаб & Не применялся & Частичный ${ }^{*}$ \\
\hline
\end{tabular}

* ИЛБЛ - купирование клинических симптомов, регрессия инфильтративных очагов по типу матового стекла; ЛПС - сокращение размеров печени, селезенки, лимфатических узлов; цитопения - купирование Кумбс-позитивной гемолитической анемии, ИТП; энтеропатия - без ответа.
+ 5 см, селезенка + 6 см из-под края реберной дуги); лабораторно-микроцитарная, гипохромная анемия до 85-90 г/л, резистентная к терапии пероральными препаратами железа. Были исключены глистные инвазии, болезнь Гоше, мембранопатии и ферментопатии эритроцитов.

В возрасте 4 лет с симптомами двустороннего поражения легких (малопродуктивный кашель, эпизоды кровохарканья, дыхательная недостаточность 2-3-й степени со снижением сатурации до 90-92\%), генерализованной лимфаденопатией, в тяжелом состоянии пациентка была впервые госпитализирована в отделение иммунологии НМИЦ ДГОИ им. Дмитрия Рогачева. По результатам МСКТ органов грудной клетки определялись множественные очаги консолидации легочной ткани по типу матового стекла (крупные, максимально - до 1,5 см), а также диффузные изменения междолькового интерстиция, увеличение лимфатических узлов средостения, корней легкого, подмышечных и надключичных областей. По данным лабораторных исследований, впервые выявлена глубокая гипогаммаглобулинемия, снижение числа переключенных В-лимфоцитов «памяти», Т-регуляторных лимфоцитов, TREC; отсутствие KREC (таблица 1).

Состояние ребенка было расценено как идиопатический гемосидероз, назначены глюкокортикостероиды в дозе 2 мг/кг/сут с постепенной отменой (рисунок 3 В). На фоне терапии ГКС наблюдался непродолжительный эффект в виде частичного купирования бронхолегочной симптоматики.

В дальнейшем по поводу сохраняющегося лимфопролиферативного синдрома, энтеропатии пациентке проводили иммуносупрессивную терапию различными препаратами, включая метотрексат, азатиоприн, сиролимус, адалимумаб (таблица 2). Однако через 3 месяца после полной отмены ГКС в возрасте 5 лет у девочки было отмечено быстрое нарастание клинических и рентгенологических симптомов поражения легких (увеличение количества и размеров очагов, фокусов уплотнения легочной ткани в обоих легких),

\section{Рисунок 4}

Патоморфологическая характеристика ИЛБЛ у пациентки № 2: А, Б - диффузная периоброхиолярная гиперплазия с формированием герминативного центра (ФБ) и единичные «саркоидозоподобные» гранулемы (НЛГ) (окраска гематоксилин-эозином, $\times 400)$ с тотальной экспрессией CD20+; В - умеренная инфильтрация интерстиция мелкими лимфоцитами с экспресией $\mathrm{CD}^{+}$

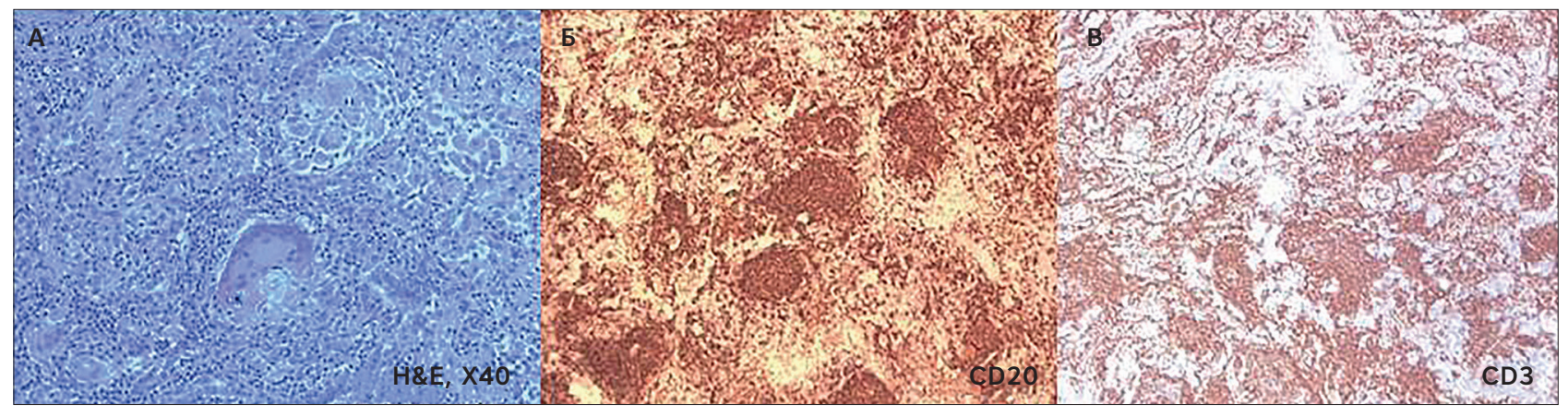


усугубление лимфопролиферативного синдрома. Микробиологический анализ бронхоальвеолярного лаважа не выявил значимых патогенных микроорганизмов. Пациентке была выполнена диагностическая торакоскопическая биопсия легкого. По результатам гистологии легочной ткани определялась реактивная гиперплазия бронхо-ассоциированной лимфоидной ткани по типу фолликулярного бронхиолита и нодулярной лимфоидной гиперплазии за счет $\mathrm{CD} 2 \mathrm{O}^{+}$ B-лимфоцитов с умеренной Т-клеточной инфильтрацией интерстиция $\left(\mathrm{CD}^{+}\right)$. По совокупности полученных данных верифицирована интерстициальная лимфоцитарная болезнь легких (рисунок 4).

Учитывая патоморфологическую характеристику ИЛБЛ (преобладающая В-клеточная фолликулярная гиперплазия), отсутствие эфффекта от проводимой ранее иммуносупрессивной терапии, пациентке ини-

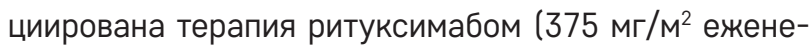
дельно, далее 1 раз в 3 мес.; всего 8 инфузий). Это привело к достижению положительной динамики не только со стороны ИЛБЛ (по данным КТ легких, уменьшение очагов консолидации легочной ткани, интерстициальных изменений), но и к уменьшению степени выраженности лимфопролиферативного синдрома (рисунки 3 В-Д).

Молекулярно-генетическая диагностика, выполненная с помощью метода нового поколения (NGS, панель ПИДС и цитопения), позволила обнаружить мутацию в гене CTLA4 c.410 > T, Pro137Leu в гетерозиготном состоянии и в возрасте 7 лет (2016 г.) подтвердить у девочки диагноз «первичный иммунодефицит, дефицит CTLA4». В дальнейшем при обследовании членов семьи носительство данной мутации с бессимптомным течением было выявлено у бабушки, мамы, родных братьев, сестер, а также у дяди девочки по линии матери, имеющего клинику CHAI (тромбоцитопения, лимфопролиферация, энтеропатия, гипогаммаглобулинемия). Такая разнородная симптоматика при одном и том же генетическом дефекте иллюстрирует различную пенетрантность дефекта, характерного для многих аутосомно-доминантных заболеваний, в частности, дефекта CTLA4 [20] (рисунок 2 Б).

В связи с наличием верифицированного дефекта в гене CTLA4 было принято решение о назначении патогенетической монотерапии абатацептом в дозе 10 мг/кг, внутривенно, 1 раз в 14 дней. В течение последующего наблюдения через 6 мес. на фоне терапии абатацептом (Оренсия) у ребенка констатировали ремиссию клинических симптомов иммунного поражения органов. По данным контрольной МСКТ органов грудной клетки, в легких не выявлено очаговых инфильтративных и интерстициальных изменений, а также увеличенных лимфатических узлов (рисунок 3 E).
В обоих случаях пациентки прекрасно переносили терапию абатацептом, никаких побочных эффектов терапии у них не отмечено.

\section{ОБСУЖДЕНИЕ РЕЗУЛЬТАТОВ ЛЕЧЕНИЯ}

Представленные в настоящей работе клинические случаи пациентов с иммунной дизрегуляцией - дефектами генов LRBA и CTLA4 - демонстрируют широкий спектр аутоиммунных осложнений ПИДС, включая развитие интерстициальной лимфоцитарной болезни легких в раннем детском возрасте.

Назначение таргетной патогенетической терапии препаратом абатацепт (Оренсия) для лечения пациентов с синдромами иммунной дизрегуляции позволяет достичь контроля над аутоиммунными осложнениями, включая ИЛБЛ.

\section{MHEHИЕ ЭКСПЕРТА}

\section{А.Ю. Щербина, профессор, заведующая отде- лением иммунологии НМИЦ ДгОИ им. Дмитрия Рогачева Минздрава России}

Интерстициальная лимфоцитарная болезнь легких как аутоиммунное/иммунное осложнение ПИДС впервые была описана менее 10 лет назад в когорте взрослых пациентов с общей вариабельной недостаточностью [21]. В дальнейшем появились сообщения о развитии ИЛБЛ у пациентов с другими видами ПИДС, однако по-прежнему в них содержатся описания единичных случаев, в основном взрослых пациентов или небольших групп [22]. Именно поэтому до сих пор нет единого алгоритма диагностики и лечения ИЛБЛ, что существенно усложняет работу клиницистов.

ИЛБЛ развивается за счет патологической фолликулярной гиперплазии бронхо-ассоциированной лимфоидной ткани или дифффузого инфильтративного повреждения интерстиция [23] и имеет четко очерченную гистологическую характеристику. Она может быть представлена тремя патоморфологическими формами: фолликулярный бронхиолит (ФБ), нодулярная лимфоидная гиперплазия (НЛГ) и лимфоцитарная интерстициальная пневмония (ЛИП), но часто наблюдается смешанный вариант [24].

Характерные для ИЛБЛ паренхиматозные и интерстициальные изменения в легких позволяют выявить МСКТ или МРТ органов грудной клетки. Так, очаги консолидации по типу матового стекла или симптом «хлопкового дерева в почках» свойственны для фолликулярного бронхиолита; крупные саркоидозоподобные гранулемы - для нодулярной лимфоидной гиперплазии, а диффузные интерстициальные 
изменения специфичны для лимфоцитарной интерстициальной пневмонии [25].

Безусловно, очень важно исключить активный инфекционный процесс в легких - это требует комплексного микробиологического исследования бронхоальвеолярного лаважа [26]. Но «золотой стандарт» подтверждения ИЛБЛ - биопсия легкого, позволяющая прежде всего исключить опухолевый процесс, частота развития которого высока у пациентов с ПИДС [27], а также дифференцировать характер лимфоидной инфильтрации с превалированием Т- или В-лимфоцитов [28].

Как показывают описанные выше клинические примеры, а также данные литературы [29-32], терапия различными иммуносупрессивными препаратами обычно дает кратковременный эффект и нередко сопровождается множественными побочными действиями. Этот факт послужил причиной поиска новых подходов к терапии с использованием таргетных препаратов. Важная роль при выборе таргетной терапии ИЛБЛ отводится типу лимфоцитарной инфильтрации [33], а также молекулярно-генетическому дефекту, обусловливающему ПИДС. Это особенно актуально для множества комбинированных первичных иммунодефицитов, которые нередко очень схожи клинически.

Синдромы дизрегуляции в данном случае - показательная модель сложной иерархии иммунологических связей. С одной стороны, у таких пациентов ИЛБЛ в большей степени характеризуется преобладанием пролиферации так называемых В-зон лимфоидных фолликулов in citu, поэтому при назначении ритуксимаба отмечают хороший клинический ответ с уменьшением очаговой инфильтрации легочной ткани на МСКТ-сканах. С другой стороны, у пациентов имеет место дизрегуляция не только на уровне бронхо-ассоциированной лимфоидной ткани, но и иммунной системы в целом, что приводит к формированию аутореактивного пула как Т-, так и В-лимфоцитов. Таким образом, в данном случае назначение химерной молекулы CTLA4 - абатацепта - как аналога естественного индуктора иммунологической толерантности приводит к достижению контроля над аутореактивностью и соответственно нивелированию симптома ИЛБЛ и других имеющихся у пациентов иммунных осложнений.

Резюмируя вышеизложенное, ИЛБЛ - это тяжелое иммунное осложнение ПИДС, существенно сокращающее продолжительность жизни. Ранняя диагностика с участием клиницистов, рентгенологов, патоморфологов, врачей молекулярной генетики, дифференцированный подход к таргетной терапии залог успеха в лечении этого осложнения ПИДС.

\section{ИСТОЧНИК ФИНАНСИРОВАНИЯ}

Не указан.

\section{КОНФЛИКТ ИНТЕРЕСОВ}

Авторы статьи подтвердили отсутствие конфоликта интересов, о котором необходимо сообщить.

\section{ORCID}

Rodina Y.A. ORCID: http://orcid.org/0000-0001-9857-4456

Shvets 0.A. ORCID: http://orcid.org/0000-0001-5347-7150

Tereshenko G.V. ORCID: http://orcid.org/0000-0001-7317-7104

Abramov D.S. ORCID: http://orcid.org/0000-0003-3664-2876

Deripapa E.V. ORCID: https://orcid.org/0000-0002-9083-4783

\section{Литература}

1. Кузьменко Н.Б., Щербина А.Ю. Классификация первичных иммунодефицитов как отражение современных представлений об их патогенезе и терапевтических подходах. Российский журнал детской гематологии и онкологии 2017; 4 (3): 51-7.

2. Mahlaoui N., Warnatz K., Jones A., Workman S., Cant A. Advances in the Care of Primary Immunodeficiencies (PIDs): from Birth to Adulthood. J Clin Immunol 2017 Jul; 37 (5):452-60.

3. Torigian D.A., LaRosa D.F., Levinson A.I., Litzky L.A., Miller W.T.Jr. Granulomatous-lymphocytic interstitial lung disease associated with common variable immunodeficiency: CT findings. J Thorac Imaging 2008; 23: 162-9.
4. Picard C., Gaspar H.B., Al-Herz W., Bousfiha A., Chatila T., Crow Y.J., et al. International Union of Immunological Societies: 2017 Primary Immunodeficiency Diseases Committee report on inborn errors of immunity. J Clin Immunol 2017 (in Press).

5. Schubert D., Bode C., Kenefeck R., Hou T.Z., Wing J.B., Kennedy A., et al. Autosomal dominant immune dysregulation syndrome in humans with CTLA4 mutations. Nat Med 2014; 20: 1410-6.

6. Alkhairy O.K., Abolhassani H., Rezaei N., Fang M., Andersen K.K., Chavoshzadeh Z., et al. Spectrum of phenotypes associated with mutations in LRBA. J Clin Immunol 2016; 36: 33-45.
7. Lo B., Abdel-Motal U.M. Lessons from CTLA-4 deficiency and checkpoint inhibition. Current Opinion in Immunology 2017, 49: 14-9.

8. Gamez-Diaz L., August D., Stepensky P., Revel-Vilk S., Seidel M.G., Noriko M., et al. The extended phenotype of LPS-responsive beige-like anchor protein (LRBA) deficiency. Allergy Clin Immunol 2016; 137 (1): 223-30.

9. Charbonnier L.M., Janssen E., Chou J., Ohsumi T.K., Keles S., Hsu J.T., et al. Regulatory T-cell deficiency and immune dysregulation, polyendocrinopathy, enteropathy, X-linked-like disorder caused by loss-of-function mutations in LRBA. J Allergy Clin Immunol 2015; 135 (1): 217-27. 
10. Lo B., Zhang K., Lu W., Zheng L., Zhang Q., Kanellopoulou C., et al. Patients with LRBA deficiency show CTLA4 loss and immune dysregulation responsive to abatacept therapy. Science 2015; 349: 436-40.

11. Takahashi T., Tagami T., Yamazaki S., Uede T., Shimizu J., Sakaguchi N., et al. Immunologic self-tolerance maintained by $\operatorname{CD} 25(+) \operatorname{CD} 4(+)$ regulatory $T$ cells constitutively expressing cytotoxic $\mathrm{T}$ lymphocyte-associated antigen 4. J Exp Med 2000; 192 (2): 303-10.

12. Rudd C.E., Taylor A., Schneider H. CD28 and CTLA-4 coreceptor expression and signal transduction. Immunol Rev 2009; 229 (1): 12-26.

13. Thompson C.B., Allison J.P. The emerging role of CTLA-4 as an immune attenuator. Immunity 1997; 7 (4): 445-50.

14. Wing K., Onishi Y., Prieto-Martin P., Yamaguchi T., Miyara M., Fehervari Z.,et al. CTLA-4 control over Foxp3+ regulatory $T$ cell function. Science 2008 ; 322 (5899): 271-5.

15. Tivol E.A., Borriello F., Schweitzer A.N., Lynch W.P., Bluestone J.A., Sharpe A.H. Loss of CTLA-4 leads to massive lymphoproliferation and fatal multiorgan tissue destruction, revealing a critical negative regulatory role of CTLA-4. Immunity 1995; 3: 541-7.

16. Waterhouse P., Penninger J.M., Timms E., Wakeham A., Shahinian A., Lee K.P., et al. Lymphoproliferative disorders with early lethality in mice deficient in Ctla-4. Science 1995; 270 : 985-8.

17. Barzaghi F., Amaya Hernandez L.C., Neven B., Ricci S., Kucuk Z.Y., Bleesing J.J., et al. Long-term follow-up of IPEX syndrome patients after different therapeutic strategies: An international multicenter retrospective study. J Allergy Clin Immunol 2018 Mar; 141 (3): 1036-49.

18. Lo B., Fritz J.M., Su H.C., Uzel G., Jordan M.B., Lenardo M.J. CHAl and LATAIE: new genetic diseases of CTLA-4 checkpoint insufficiency. Blood 2016; 128 (8): 1037-42.
19. Important Safety Information for ORENCIA $®$ (abatacept). Prescribtion. Bristol-Myers Squibb Company, 427US1800504-01-01, Mar/18.

20. Кузьменко Н.Б., Варламова Т.В., Мерсиянова И.В., Райкина Е.В., Бобрынина В.О., Щербина А.Ю. Молекулярно-генетическая диагностика первичных иммунодефицитных состояний. Вопросы гематологии/онкологии и иммунопатологии в педиатрии 2016; 15 (1): 10-6.

21. Hurst J.R., Verma N., Lowe D., Baxendale H.E., Jolles S., Kelleher P., et al. British Lung Foundation/United Kingdom Primary Immunodeficiency Network Consensus Statement on the Definition, Diagnosis, and Management of Granulomatous-Lymphocytic Interstitial Lung Disease in Common Variable Immunodeficiency Disorders. J Allergy Clin Immunol Pract 2017; 5: 938-45.

22. Schussler E., Beasley M.B., Maglione P.J. Lung Disease in Primary Antibody Deficiencies. American Academy of Allergy, Asthma \& Immunology 2016 Nov-Dec; 4 (6): 1039-52.

23. Poletti V., Ravaglia C., Tomassetti S., Gurioli C., Casoni G., Asioli S., et al. Lymphoproliferative lung disease. Eur Respir Rev 2013; 22: 427-36.

24. Guinee D.G.Jr. Update on nonneoplastic pulmonary lymphoproliferative disorders and related entities. Arch Pathol Lab Med 2010; 134: 691-701.

25. Maglione P.J., Overbey J.R., Cunningham-Rundle C. Progression of CVID Interstitial Lung Disease Accompanies Distinct Pulmonary and Laboratory Findings. J Allergy Clin Immunol Pract 2015; 3 (6): 941-50.

26. Jesenak M., Banovcin P., Jesenakova B., Babusikova E. Pulmonary manifestations of primary immunodeficiency disorders in children. Front Pediatr 2014; 2: 77.

27. Дерипапа Е.В., Швец О.А., Абрамов Д.С., Мякова Н.В., Щербина А.Ю. Анализ частоты развития лимфом у детей с первичными иммунодефицитными состояниями. Вопросы гематологии/онкологии и иммунопатологии в педиатрии 2016; 15 (1): 61-5.
28. Rao N., Mackinnon A.C., Routes J.M. Granulomatous and Lymphocytic Interstitial Lung Disease (GLILD): A Spectrum of Pulmonary Histopathological Lesions in Common Variable Immunodeficiency (CVID) Histological and Immunohistochemical Analysis of 16 cases. Hum Pathol 2015; 46 (9): 1306-14.

29. Boursiquot J.-N., Gérard L., Malphettes M., Fieschi C., Galicier L., Boutboul D., et al. Granulomatous Disease in CVID: Retrospective Analysis of Clinical Characteristics and Treatment Efficacy in a Cohort of 59 Patients. J Clin Immunol 2013; 33: 84-95.

30. Davies C.W., Juniper M.C., Gray W., Gleeson F.V., Chapel H.M., Davies R.J.O., et al. Lymphoid interstitial pneumonitis associated with common variable hypogammaglobulinaemia treated with cyclosporin A. Thorax 2000; 55: 88-90.

31. Franxman T.J., Howe L.E., Baker J.R.Jr. Infliximab for treatment of granulomatous disease in patients with common variable immunodeficiency. J Clin Immunol 2014; 34: 820-7.

32. Pathria M., Urbine D., Zumberg M.S., Guarderas J. Management of granulomatous lymphocytic interstitial lung disease in a patient with common variable immune deficiency. BMJ Case Rep 2016 Jun; 22.

33. Chase N.M., Verbsky J.W., Hintermeyer M.K., Waukau J.K., TomitaMitchell A., Casper J.T., et al. Use of combination chemotherapy for treatment of granulomatous and lymphocytic interstitial lung disease (GLILD) in patients with common variable immunodeficiency (CVID). J Clin Immunol 2013; 33: 30-9. 